\title{
Effect of Sulfonation on Thermal, Mechanical, and Electrical Properties of Blends Based on Polysulfones
}

\author{
By Amelia LINARES ${ }^{1, *}$ and Rosario BENAVENTE ${ }^{2}$
}

Different blends based on polysulfone (PSU), polyethersulfone (PES) and polyimide (PI) were prepared and characterized by Fourier transform IR spectroscopy, differential scanning calorimetry, dynamic-mechanical analysis, and microhardness. Subsequently, polysulfone and polyethersulfone homopolymers were sulfonated by treatment with chlorosulfonic acid. Then, analogous blends to the non-sulfonated ones were obtained and studied through the analysis of their glass transition temperature, microhardness, and electrical behaviour. In addition, a statistical method, suitable for the design of systems with optimized behaviour, has been applied to study these polymer blends and to predict the compositions with the best properties. KEY WORDS: Poly(arylene ether sulfone) / Ionomers / Mechanical Properties / Glass Transition Temperature / Conducting Polymers /

Research on the area of polymer electrolyte membrane fuel cells has increased markedly over the last few years. ${ }^{1-5}$ Polymer electrolyte, or proton exchange membrane, fuel cells (PEMFC) are devices that convert (directly or via a reformation) the free energy of a fuel source, such as hydrogen, methanol, methane, gasoline, etc., to dc power. The conversion of fuel liberates free electrons, which can be used to do work, and protons that, after crossing the polymer membrane, react with a source of oxygen, usually air, to form water.

Nowadays, Nafion, which is commercially available in various molecular weights and ionic concentrations, is the dominant membrane material for PEMFC. However, there are several disadvantages of using Nafion as polymer electrolyte such as: (1) the low operation temperature $\left(\sim 90^{\circ} \mathrm{C}\right)$; (2) the significant crossover when the fuel is direct methanol; (3) the loss of dimensional stability; (4) the difficulty on water management; (5) the environmental pollution; (6) the high cost, etc. Hence, there is a recognized need for synthesising alternative polymeric proton exchange membranes. The new materials must be capable of performing for many thousands of hours at high temperatures under the rigorous acidic and free radical-rich environment of a proton exchange membrane fuel cell. For direct methanol fuel cells, they also must have a greatly reduced permeability to methanol, as compared to Nafion.

Currently, poly(arylene ether sulfone)s have achieved special importance for this purpose. Poly(arylene ether sulfone)s are engineering thermoplastic materials that display a wide variety of desirable properties, including high modulus (stiff), and good hydrolytic, oxidative, and thermal stability. Usually, they are thermoplastic and amorphous materials with relatively high glass transition temperature, in the range of $180-250{ }^{\circ} \mathrm{C}$, depending on the structure of the backbone. Common backbone characteristics include rigid phenylene groups connected by flexible ether and sulfone linkages. The rigidity, which is usual in this class of polymers, is associated with the inflexible phenyl groups, while the toughness is ascribed to the mobility of the ether linkages. ${ }^{6}$ These polymers are good candidates for high temperature or chemically aggressive applications due to their excellent thermal, chemical, and oxidative stabilities. Moreover, they have very good hydrolytic stability compared to other thermoplastic polymers such as polycarbonates, polyesters, and polyetherimides. ${ }^{7}$

The presence of phenylene groups makes possible the incorporation of sulfonic groups into the polymer chain through a reaction of sulfonation. Therefore, a proton conducting polymer will be obtained and the low hydrophilic behaviour of polysulfones will be clearly improved. High water absorption capacity is an indispensable requirement to consider a polymer as electrolyte in a fuel cell. In the presence of water, sulfonic groups dissociate into $\mathrm{SO}_{3}{ }^{-}$(fixed charge) and $\mathrm{H}^{+}$(mobile charge). In this sense, many publications deal with the synthesis of these sulfonated polymers. Up to date, various methods have been proposed to introduce sulfonic acid groups into the poly(arylene ether sulfone)s. These include modification in heterogeneous and homogeneous media using sulfuric acid, ${ }^{8}$ chlorosulfonic acid, ${ }^{9}$ trimethyl chlorosilane, ${ }^{10}$ via direct polymerization, ${ }^{11}$ treatment with sulphur trioxidetriethyphosphate complex, ${ }^{12}$ etc.

This work is undertaken with the aim of preparing new membranes, with good electrical and mechanical properties, that can be an alternative to the commercial Nafion. The objective is to carry out a reaction of sulfonation with two types of poly(arylene ether sulfone)s and to analyze the effect on the physical, mechanical and electrical properties, as well as, to study the behaviour of different blends based on both, pristine and sulfonated polymers, and one polyimide (because of its excellent thermal and mechanical properties).

The relevance that polymer blends have recently acquired, as an alternative to the chemical synthesis of new and advanced materials, does not need to be stressed at all. Because, a priori, the number of necessary compositions to study the general

\footnotetext{
${ }^{1}$ Instituto de Estructura de la Materia (CSIC), c/ Serrano 12128006 Madrid (Spain)

${ }^{2}$ Instituto de Ciencia y Tecnología de Polímeros (CSIC), c/ Juan de la Cierva, 328006 Madrid (Spain)

*To whom correspondence should be addressed (Tel: +34-91-561-6800, Fax: +34-91-585-5184, E-mail: alinares@iem.cfmac.csic.es).
} 
behaviour of a blend is unlimited, the design of experiences constitutes a tool of undeniable value if a functional relationship can be established between the properties measured and the concentration of each polymer with a minimum number of tests. In this sense, we have used the classical Scheffé Simplex Model, a statistical design, to plan the compositions of our polymer blends with the aim to obtain empirical equations that satisfactorily describe the properties of the blends over the whole range of compositions.

\section{EXPERIMENTAL}

\section{Materials}

Homopolymers, solvents and reagent were used as supplied, without previous purification. Polysulfone, polyethersulfone and chlorosulfonic acid (used as sulfonation reagent) were supplied by Aldrich; polyimide (Matrimid 5218) was delivered by Ciba Geiby; dimethylformamide (DMF) and dimethylacetamide (DMA) were acquired from Scharlau, and methylene chloride and chloroform were delivered by SDS. De-ionized water used for washing purposes was milli-Q quality.

\section{Sulfonation of Polymers and Procedures}

Both homopolymers were sulfonated following a similar procedure as proposed by Smitha et al. ${ }^{13}$ In order to eliminate any small amount of water, prior to sulfonation reaction, homopolymers were vacuum-dried in a desiccator at $80^{\circ} \mathrm{C}$ for $48 \mathrm{~h}$, and solvents were dried on molecular sieves. A solution of ten grams of homopolymer and $100 \mathrm{~mL}$ of dried solvent was transferred to a three-neck flask, under nitrogen atmosphere, and kept at room temperature under continuous mechanical stirring. Then, a $5 \%(\mathrm{v} / \mathrm{v})$ solution of chlorosulfonic acid in $100 \mathrm{~mL}$ of solvent was transferred into a dropper and gradually added to the polymer solution. DCE was used as solvent for PSU and DCM in the case of PES. The reaction solution was kept homogeneous at room temperature for $1 \mathrm{~h}$ in the case of PSU and $48 \mathrm{~h}$ for PES. The precipitated polymers, i.e., sulfonated polysulfone (SPSU) and sulfonated polyethersulfone (SPES), brown and dark yellow in colour, respectively, were washed several times with milli-Q water until neutral $\mathrm{pH}$ was reached, and dried at vacuum and $80^{\circ} \mathrm{C}$ for $4 \mathrm{~d}$. Finally, they were stored in dry environment until use.

Different polymer blends were obtained by dissolving the corresponding amounts of homopolymers, sulfonated polymers, or polyimide in a suitable solvent: chloroform in the case of PSU; methylene chloride for PES and PI; dimethylformamide and dimethylacetamide for SPSU and SPES, respectively. After solvent evaporation and vacuum drying for $4 \mathrm{~d}$ at 80 or $120^{\circ} \mathrm{C}$ (depending on the solvent), samples in the form of films were obtained, and then the different tests and measurements were carried out. As it has previously mentioned, the compositions of the blends were planned in such a way that a statistical method was applied to study and optimize these systems.

\section{Elemental Analysis}

Sulfur content was determined with a LECO mod. CHNS932 elemental analyzer.

\section{Fourier Transform Infrared (FT-IR) Spectroscopy}

FT-IR spectroscopy was carried out on a Perkin Elmer FTIR spectrometer using the attenuated total refection (ATR) technique.

\section{Differential Scanning Calorimetry (DSC)}

DSC was carried out with a Mettler TA 4000 differential scanning calorimeter. The thermograms were recorded at $20^{\circ} \mathrm{C} / \mathrm{min}$ and $T_{\mathrm{g}}$ was taken in the inflection point of the variation of specific heat in that region. For each system, three thermograms from different samples were recorded, being the average value of them considered as the value of glass transition temperature.

\section{Dynamic Mechanical Analysis (DMA)}

A DMTA V dynamic mechanical thermal analyzer from Rheometric Scientific was used. The measurements were implemented between 40 and $250-320^{\circ} \mathrm{C}$ at a heating rate of $2{ }^{\circ} \mathrm{C} / \mathrm{min}$. The complex modulus and loss tangent of the samples were determined at $0.1 \mathrm{~Hz}$. The technique was applied under bending with single cantilever geometry.

\section{Tensile Measurements}

The tensile strain properties were measured on a universal Instron machine (model 4301) according to standard UNE-EN ISO 527-3. The samples were small in size and of the Halterian type. The test was run at a rate of $10 \mathrm{~mm} / \mathrm{min}$ at room temperature. For each sample, three measurements were carried out, the mean value being established as the mechanical property.

\section{Microhardness (MH)}

A Vickers indentor attached to a Leitz microhardness tester was used to carry out microndentations at room temperature. A contact load of $0.98 \mathrm{~N}$ and a contact time of $25 \mathrm{~s}$ were employed. $\mathrm{MH}$ values (in $\mathrm{MPa}$ ) were calculated according to the relationship:

$$
\mathrm{MH}=2 \sin 68^{\circ} \mathrm{P} / \mathrm{d}^{2}
$$

Where $\mathrm{P}$ (in $\mathrm{N}$ ) is the contact load and $\mathrm{d}$ (in $\mathrm{mm}$ ) is the diagonal length of the project indentation area.

\section{Complex Impedance Spectroscopy}

A computer-assisted Hewlett Packard 4192A Impedance Spectroscopy Analyzer was used for impedance spectroscopy determination. The measurements were carried out in the two-electrode AC impedance mode, at ambient temperature, in the frequency range $0.01-10000 \mathrm{~Hz}$. The voltage applied was $0.1 \mathrm{~V}$ amplitude. To measure the conductivity, the sample was sandwiched between two $0.07 \mathrm{~cm}^{2}$ silver electrodes. 


\section{Statistical Analysis}

The experimental compositions were planned in order to apply a statistical method to study and optimize these systems. In general, with the aim of obtaining new materials with desirable properties, the usual procedure is to prepare, at random, more or less complicated mixtures of the different components and to select the most suitable empirically. However, there are different mathematical models that have been proposed to solve this problem. The purpose is to determine the more favourable blend, i.e., to find the proportions of the components required to optimize one or more properties, and to obtain empirical equations, which satisfactorily describes the properties over the whole area of composition without the need of experimental determination. In the general case, these empirical mathematical models, also named equation of response surfaces, are polynomials, ${ }^{14,15}$ and correspond to the development of Taylor serial functions.

In the present paper, a classical Scheffé Simplex design, ${ }^{16}$ which is well suited for different types of mixtures, ${ }^{17}$ has been used. To determine the coefficients of a particular model, Scheffé proposed the study of mixtures whose compositions are distributed symmetrically in a "simplex" lattice over the experimental range. This kind of design contains a number of experimental points equal to the coefficients in the corresponding polynomial that allows the equations to be solved directly, taking into account that the more experiences are carried out to obtain the equations, the more accurate the model is. In our case, the blends were prepared according the following plan:

\begin{tabular}{cllll}
\hline \multirow{2}{*}{$\begin{array}{c}\text { Experience } \\
\text { number }\end{array}$} & SAMPLE & \multicolumn{3}{c}{ Variables } \\
\cline { 3 - 5 } & & $\mathrm{X}_{1}$ & $\mathrm{X}_{2}$ & $\mathrm{X}_{3}$ \\
\hline 1 & PSU & 1 & 0 & 0 \\
2 & PES & 0 & 1 & 0 \\
3 & PI & 0 & 0 & 1 \\
4 & PSUPES & 0.5 & 0.5 & 0 \\
5 & PSUPI & 0.5 & 0 & 0.5 \\
6 & PESPI & 0 & 0.5 & 0.5 \\
7 & PSUPESPI & 0.33 & 0.33 & 0.33 \\
\hline
\end{tabular}

Analogous treatment was applied to the corresponding sulfonated samples.

The following conditions have to be fulfilled:

$$
\begin{aligned}
& \Sigma_{\mathrm{i}} \mathrm{X}_{\mathrm{i}}=1 \\
& 0 \leq \mathrm{X}_{\mathrm{i}} \leq 1
\end{aligned}
$$

where $X_{i}$ is the weight fraction of each component in the blend.

With the results of the experiments, using the NEMROD 3.1 software from L.P.R.A.I., Ltd., ${ }^{18}$ the coefficients of the surfaceresponse equations:

$$
\begin{aligned}
Y= & b_{1} X_{1}+b_{2} X_{2}+b_{3} X_{3}+b_{12} X_{1} X_{2} \\
& +b_{13} X_{1} X_{3}+b_{23} X_{2} X_{3}+b_{123} X_{1} X_{2} X_{3}
\end{aligned}
$$

were calculated. $\mathrm{Y}$ is the property under study.

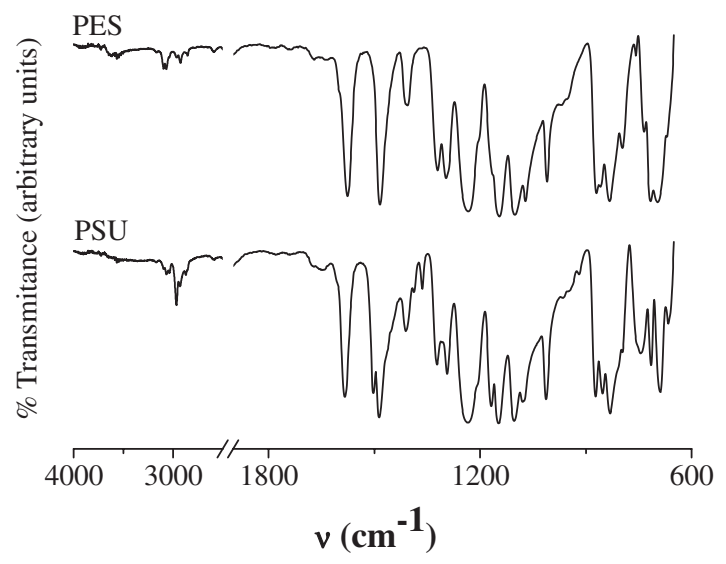

Figure 1. FT-IR spectra of the PES and PSU homopolymers.

\section{RESULTS AND DISCUSSION}

\section{Non-sulfonated Systems}

Figure 1 shows IR spectra corresponding to pristine PSU and PES homopolymers. For PES, several intense bands are observed. One at $1296 \mathrm{~cm}^{-1}$ is due to the asymmetric stress vibration of the $\mathrm{S}=\mathrm{O}$ bond and another at $1145 \mathrm{~cm}^{-1}$ corresponds to the symmetric stress vibration of the same bond. The quite intense band at $1236 \mathrm{~cm}^{-1}$ is attributable to the symmetric stress vibration of the aromatic ether bond C-O-C. The absorption bands of the phenyl groups appear at 687 and $758 \mathrm{~cm}^{-1}$ and those due to the C-C bond vibration at 1580 , 1483 and $1405 \mathrm{~cm}^{-1}$. In the case of PSU an absorption band, which is characteristic of the aromatic ether, appears at 1234 $\mathrm{cm}^{-1}$ and it is attributable to the symmetric stress vibration of the $\mathrm{C}-\mathrm{O}-\mathrm{C}$. The absorption bands, corresponding to the methyl group of the bisphenol A group, are situated at 1364 and $1387 \mathrm{~cm}^{-1}$. The absorption due to the asymmetric stress vibration of the $\mathrm{S}=\mathrm{O}$ bond appears at $1294 \mathrm{~cm}^{-1}$, and that of the symmetric stress at $1148 \mathrm{~cm}^{-1}$. Finally, we have to highlight the band at $699 \mathrm{~cm}^{-1}$ representing the phenyl group vibration.

The compatibility of the blends was assessed by determining the glass transition temperature $\left(T_{\mathrm{g}}\right)$. Table I compiles the data corresponding to $T_{\mathrm{g}}$ obtained from DSC and DMA measurements. All samples, including the ternary blend, display a single $T_{\mathrm{g}}$, which varies as a function of blend composition. In the case of DMA measurements, the glass transition temperature was obtained from $E^{\prime \prime}$-maximum (Figure 2) because it provides similar information than $\tan \delta$, but the different relaxation processes are more evident, and it relates much better to the value obtained by DSC. ${ }^{19}$ Both techniques give analogous results indicating that, a priori, we are dealing with blends, which, at least from a macroscopic point of view, behave like totally miscible.

There are several proposed equations in literature to predict the $T_{\mathrm{g}}$ of a blend as a function of the glass temperature of the components, such as the so-called Wood ${ }^{20}$ equation: 
Table I. Values of glass transition temperature obtained from DSC and DMA measurements, and by applying different theoretical equations. Young's modulus, storage modulus and microhardness, measured at room temperature, for non-sulfonated systems

\begin{tabular}{|c|c|c|c|c|c|c|c|c|c|}
\hline SAMPLE & $\begin{array}{c}\text { Composition, wt \% } \\
\text { (PSU/PES/PI) }\end{array}$ & $\begin{array}{c}T_{\mathrm{g}, \mathrm{DSC}} \\
\left({ }^{\circ} \mathrm{C}\right)\end{array}$ & $\begin{array}{c}T_{\text {g,DMTA }} \\
\left({ }^{\circ} \mathrm{C}\right)\end{array}$ & $\begin{array}{l}\text { Wood } \\
\left({ }^{\circ} \mathrm{C}\right)\end{array}$ & $\begin{array}{l}\text { Fox } \\
\left({ }^{\circ} \mathrm{C}\right)\end{array}$ & $\begin{array}{c}\text { Pochan } \\
\left({ }^{\circ} \mathrm{C}\right)\end{array}$ & $\begin{array}{c}E \\
(\mathrm{MPa})\end{array}$ & $\begin{array}{c}E^{\prime} \\
(\mathrm{MPa})\end{array}$ & $\begin{array}{c}\mathrm{MH} \\
(\mathrm{MPa})\end{array}$ \\
\hline PSU & $100 / 0 / 0$ & 189 & 188 & 188 & 188 & 188 & 1940 & 1480 & 136 \\
\hline PES & $0 / 100 / 0$ & 223 & 224 & 224 & 224 & 224 & 1590 & 1310 & 101 \\
\hline $\mathrm{PI}$ & $0 / 0 / 100$ & 309 & 318 & 318 & 318 & 318 & 2551 & 2290 & 249 \\
\hline PSUPES & $50 / 50 / 0$ & 205 & 202 & 206 & 205 & 205 & 1685 & 1390 & 112 \\
\hline PSUPI & $50 / 0 / 50$ & 213 & 230 & 249 & 235 & 242 & 2080 & 1620 & 148 \\
\hline PESPI & $0 / 50 / 50$ & 229 & 244 & 266 & 259 & 262 & 1800 & 1460 & 116 \\
\hline PSUPESPI & 33.3/33.3/33.3 & 271 & 260 & 240 & 231 & 235 & 2150 & 2010 & 216 \\
\hline
\end{tabular}

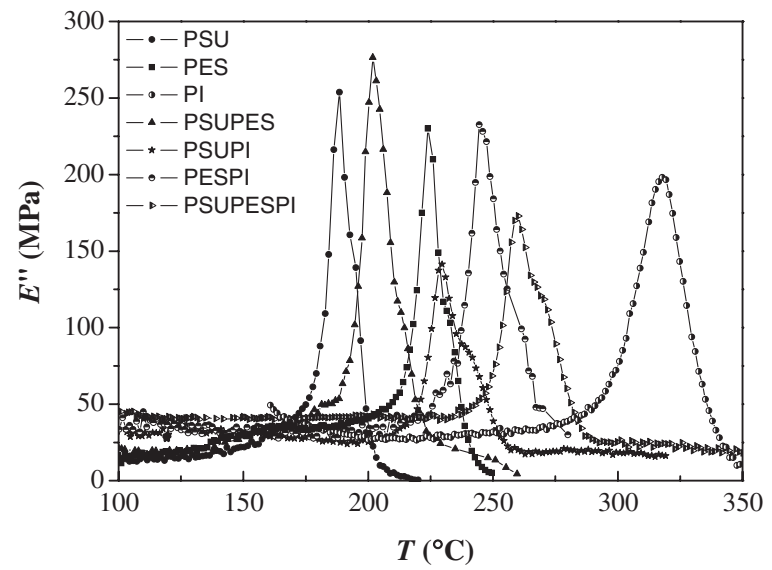

Figure 2. Imaginary component of complex modulus versus temperature for different samples at $0.1 \mathrm{~Hz}$.

$$
T_{\mathrm{g}}=\mathrm{w}_{1} T_{\mathrm{g}, 1}+\mathrm{w}_{2} T_{\mathrm{g}, 2}
$$

the Fox equation: ${ }^{21}$

$$
1 / T_{\mathrm{g}}=\mathrm{w}_{1} / T_{\mathrm{g}, 1}+\mathrm{w}_{2} / T_{\mathrm{g}, 2}
$$

and the Pochan equation: $:^{22}$

$$
\ln T_{\mathrm{g}}=\mathrm{w}_{1} \ln T_{\mathrm{g}, 1}+\mathrm{w}_{2} \ln T_{\mathrm{g}, 2}
$$

where the subscripts 1 and 2 refer to the components.

These three elementary models may be considered as "idealized" equations and presuppose additivity of specific volumes, which is equivalent to additivity of the relevant free volumes of the components. When the volume additivity rule is fulfilled, there is compensation between the energetic terms (interactions) and entropic configurations (free volume). Negative deviations from this rule suggest the existence of hetero-contact formation within the blend that may be accompanied by local interchain orientation, contributing to conformational entropy changes. The smaller the induced interchain orientation by hetero-contact formation, the larger the mobility in the neighbourhood of the contacts and the probability of related conformational entropy changes, causing an equivalent increase of the "free volume" within the blend, i.e., a corresponding decrease of the blend $T_{\mathrm{g}}$, which finally can be situated below the values predicted by additivity rules. Vice versa, the corresponding argument will hold for blends with higher interchain orientation induced by intense exothermic hetero-contact, such as those occurring in the charge transfer complexes or electron donor-receptor interactions. ${ }^{23,24}$

With the aim of studying our series qualitatively, we compare in Table I the $T_{\mathrm{g}}$ obtained experimentally with the respective ones derived by applying equations (5) to (7). Analyzing these results, only in the case of the binary blend PSUPES the experimental values fit quite well to the predict ones. On the contrary, the binary blends PSUPI and PESPI show a different behaviour. For these blends, the values of $T_{\mathrm{g}}$ determined experimentally are lower than those calculated from the mathematical models. This is indicative of the fact that, when the common component is PI, conformational arrangements provoke an increase in free volume and, hence, a drop of the glass transition temperature. The ternary blend presents an opposite behaviour since the experimental value is higher than the predicted one, suggesting the prevalence of energetic factors. The values obtained experimentally by DMA adjust much better to the predicted ones because this technique is especially sensitive to the chemical and physical structure of polymers and, as a general rule, provide more information than thermal analysis about a material, over a wide temperature and frequency range.

Regarding the values of Young's modulus and storage modulus derived from tensile and DMA measurements, respectively, these systems can be considered as stiff materials (Table I).

Nowadays, microhardness $(\mathrm{MH})$ is considered not only a routine measurement of the material hardness, but also an investigation method and an adequate tool for determining the structure and mechanical properties of polymeric materials. It has been established that Vickers microhardness is sensitive to many structural parameters as well as to the mechanical behavior. ${ }^{25}$ Hence, it is possible to connect the classical mechanical measurements, as stress-strain deformation, with microhardness and to provide information about the resistance of the material to plastic deformation and, as consequence, an idea about the local strain.

The results obtained in our research are compiled in Table I. Figure 3 shows the variation of Vickers $\mathrm{MH}$ as a function of the glass transition temperature determined by DSC. The measurements were performed at room temperature, which is below $T_{\mathrm{g}}$. As it can be inferred, the variation is linearly dependent. The obtained values are higher than the corresponding to other semicrystalline polymers such as PE and PP, 


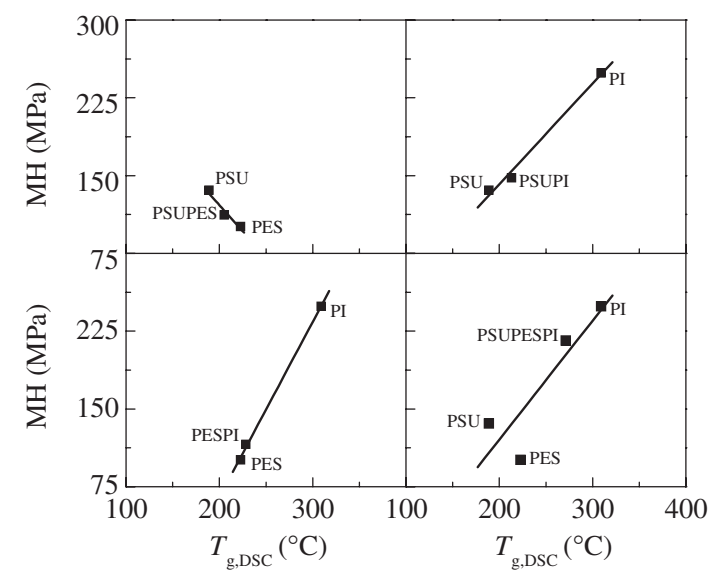

Figure 3. Dependence of the microhardness with glass transition temperature for non-sulfonated systems.

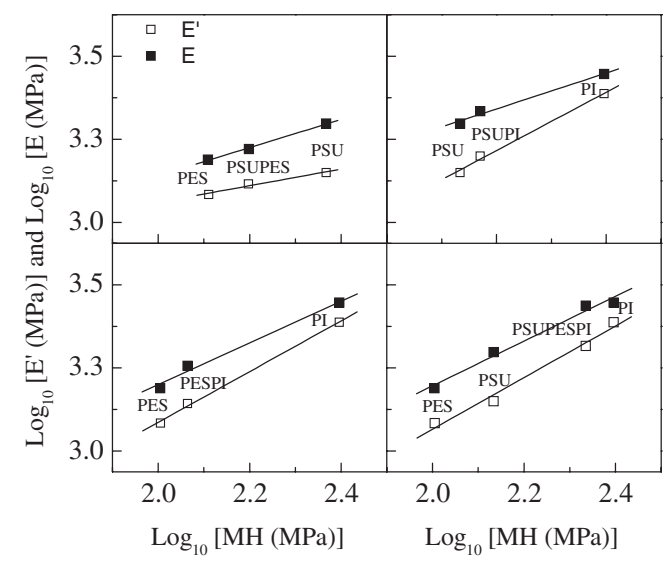

Figure 4. Elastic modulus (given by DMTA and tensile test) against microhardness for the indicated samples.

whose $T_{\mathrm{g}}$ is below room temperature. However, when they are compared with other amorphous polymers, with higher glass transition temperature, it has been found a similar relationship. $^{26}$

A direct relationship is commonly found between the Young's modulus (given by either DMA or uniaxial deformation) and microhardness, ${ }^{27}$ and the following empirical equation has been proposed:

$$
\mathrm{MH}=\mathrm{aE}^{\mathrm{b}}
$$

where $a$ and $b$ are constants. This equation is fulfilled in many systems in a very broad range of $\mathrm{MH}$ and $E$ values from thermoplastic elastomers to very rigid polymers. ${ }^{26,27}$

The blends under study show a good linear relationship $\log -\log$ scale when plotting $\log \mathrm{MH}$ vs. $\log E$, as depicted in Figure 4 for both elastic modulus, i.e., $E$ and $E^{\prime}$, obtained from uniaxial stretching and DMA measurements, respectively.

\section{Sulfonated Systems}

For both polymers, PSU and PES, the post-sulfonation reaction consists of the electrophilic substitutions, at random,

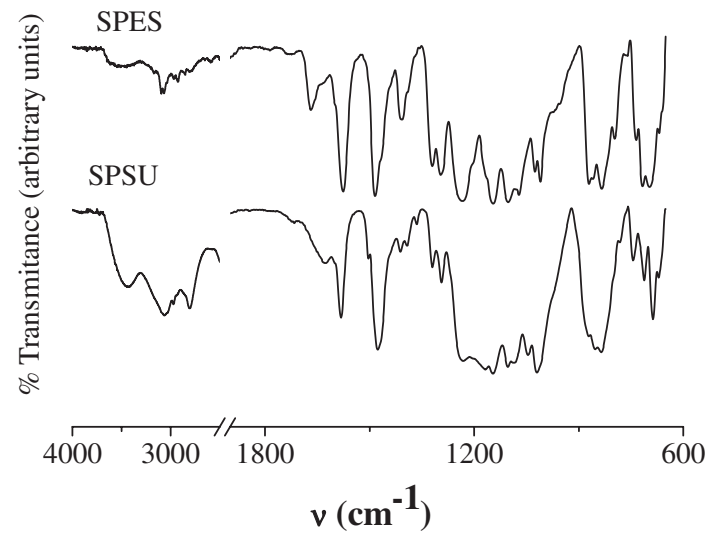

Figure 5. FT-IR spectra of the SPES and SPSU homopolymers.

of sulfonic acid groups $\left(-\mathrm{SO}_{3} \mathrm{H}\right)$ into the aromatic rings, being ortho positions of the ether function the most favourable. As result, partially sulfonated polymers (SPSU and SPES) are obtained.

Quantitatively, the level of sulfonation was determined by elemental analysis, yielding a sulphur content of $10 \%$ and $8 \%$ for SPSU and SPES, respectively, at the experimental established conditions.

Qualitatively, the sulfonation was verified by IR spectroscopy. In Figure 5, spectra of SPES and SPSU polymers are shown. The most remarkable characteristic is the appearance of a broad peak, approximately at $3400 \mathrm{~cm}^{-1}$, which is due to stretching of hydroxyl groups of $-\mathrm{SO}_{3} \mathrm{H}$. In this case, the absorption band due to ether group overlaps to the most characteristic and intense band associated to the asymmetric stretching vibrations of $-\mathrm{SO}_{3} \mathrm{H}$ group, which appears in the region between $1250-1140 \mathrm{~cm}^{-1}$. Nonetheless, SPSU shows a peak, in the range of $1175-1150 \mathrm{~cm}^{-1}$, associated to symmetric $\mathrm{O}-\mathrm{H}$ stretching and the corresponding to the symmetric $\mathrm{S}=\mathrm{O}$ stretching, which appears at $1350-1340 \mathrm{~cm}^{-1}$. SPES displays the band at 1028 corresponding to symmetric $-\mathrm{SO}_{3} \mathrm{H}$ stretching.

In this point, it is worth to take in mind some considerations. In a general sense, an ionomer is a polymer containing a few number of ionic groups linked directly to the macromolecular backbone. Hence, sulfonated polymers belong to this class of materials. The theoretical model proposed by Eisenberg, Hird and Moore (EHM), ${ }^{28}$ to explain the relationship between properties and morphology, postulates that ionomers exhibit notable differences from their initial constituents, since as a result of strong electrostatic attractive forces (opposite to the elastic ones), the ionic groups, incorporated at random, form ion pairs. ${ }^{29}$ These ion pairs aggregate and form quadruplets, sextuplets, and higher aggregates, collectively called multiplets. The multiplets cause a restriction of the mobility of the polymer segments adjacent to the multiplet. With increasing ion content, the partially immobilized regions begin to overlap. Eventually, when the ion content is high enough, these overlapped regions of immobilized segments begin to form sufficiently large domains, the so-called "cluster," in which the 
Table II. Experimental and theoretical glass transition temperature, and microhardness values for sulfonated systems

\begin{tabular}{lcccccc}
\hline \multicolumn{1}{c}{ SAMPLE } & $\begin{array}{c}\text { Composition, wt \% } \\
\text { SPSU/SPES/PI }\end{array}$ & $\begin{array}{c}T_{\mathrm{g}, \mathrm{DSC}} \\
\left({ }^{\circ} \mathrm{C}\right)\end{array}$ & $\begin{array}{c}\text { Wood } \\
\left({ }^{\circ} \mathrm{C}\right)\end{array}$ & $\left({ }^{\circ} \mathrm{C}\right)$ & $\left({ }^{\circ} \mathrm{C}\right)$ & $\begin{array}{c}\text { Fox } \\
(\mathrm{MPa})\end{array}$ \\
\hline SPSU & $100 / 0 / 0$ & 157 & 157 & 157 & 157 & 99 \\
SPES & $0 / 100 / 0$ & 231 & 231 & 231 & 231 & 218 \\
PI & $0 / 0 / 100$ & 309 & 309 & 309 & 309 & 249 \\
SPSUSPES & $50 / 50 / 0$ & 204 & 194 & 187 & 190 & 153 \\
SPSUPI & $50 / 0 / 50$ & 211 & 233 & 208 & 220 & 159 \\
SPESPI & $0 / 50 / 50$ & 215 & 270 & 264 & 267 & 195 \\
SPSUSPESPI & $33.3 / 33.3 / 33.3$ & 234 & 230 & 218 & 212 & 207 \\
\hline
\end{tabular}

material exhibits phase-separated behaviour. In this situation, a second glass transition temperature, at higher temperatures than that of the matrix, can be observed. Simultaneously, this restriction in the movement provokes new arrangements with changes in free volume. Both behaviours are reflected in $T_{\mathrm{g}}$ (increase or decrease) depending on which of the two effects prevails.

In our case, one practical result of this fact was the difficulty of manufacturing specimens with these materials because, from a technological point of view, they became very stiff and brittle. Hence, it was impossible to prepare samples in order to carry out dynamic-mechanical and tensile tests.

Table II compiles the data obtained from MH measurements, and experimental values of $T_{\mathrm{g}}$, as well as the calculated ones by applying equations (5) to (7). Regarding the unblended sulfonated polymers, sulfonation causes changes of $T_{\mathrm{g}}$ 's value, but phase-separated behaviour is not observed. In this sense, the value of the glass transition temperature of the SPSU is significantly smaller than the corresponding to non-sulfonated homopolymer, PSU, whereas in case of SPES a slight increase is observed. For blends, the observed behaviour is very similar to non-sulfonated systems and none of the proposed relationships describe the actual behaviour of these systems. In this case, the measured $T_{\mathrm{g}}$ for the binary SPSUSPES blend and the ternary one is higher than the obtained when applying the previously mentioned relations. That it is to say, the existence of strong hetero-interactions among ionic groups, inhibits the segmental movements and hence an increase of $T_{\mathrm{g}}$ is observed. The two remaining binary blends show a different behaviour and their experimental glass transition temperatures are lower than the predicted ones from equations. This fact suggests that the incorporation of PI prevents hetero-interactions and the entropic factors impose on the energetic ones diminishing the glass transition temperature.

Figure 6 shows the variation of $\mathrm{MH}$ as a function of $T_{\mathrm{g}}$ for the sulfonated polymers and their blends. Analogously to nonsulfonated systems, a quite good linear relationship is found. Hence, if we admit the fulfilment of equation (8), a direct relation can be proposed between Young's modulus and glass transition temperature. Thus, it is likely that materials with the highest microhardness have the highest modulus.

The electrical properties were determined by means of complex impedance spectroscopy. Although the measurements were taken at room temperature, prior to measuring the samples were hydrated by immersion in deionized water at

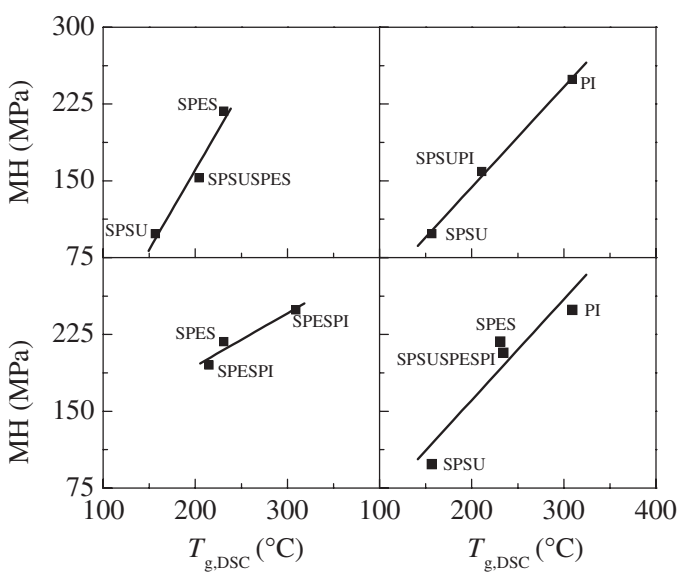

Figure 6. Dependence of the microhardness with the glass transition temperature for sulfonated polymers.

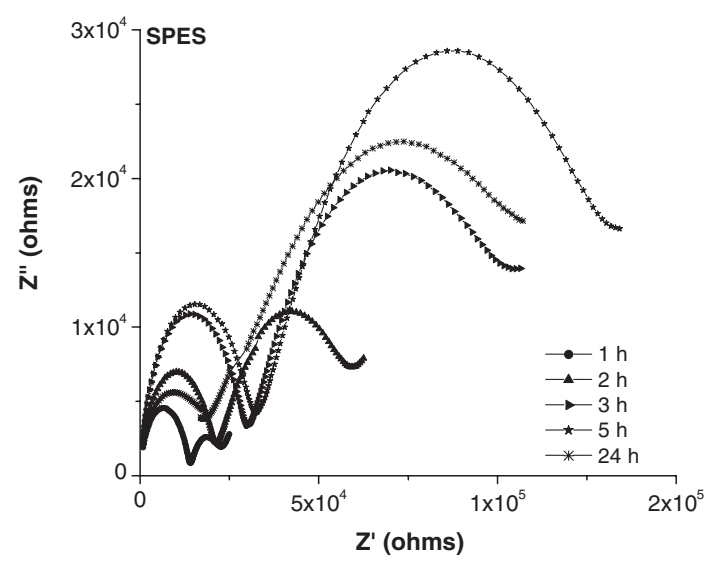

Figure 7. Complex plane diagram for SPES at different hydration times.

$50{ }^{\circ} \mathrm{C}$ for different periods. Imaginary versus real impedance plots, similar to the illustrated in Figure 7, were obtained. By using a suitable software that let us fit the data to a circular model, we inferred the resistance of he sample from the intercept of the low-frequency part of the arc on the real impedance axis, $Z^{\prime}$. The overall conductivity of the membranes was calculated, as usual. The results are shown in Table III.

The ion conductivity of the two non-sulfonated homopolymers is below $10^{-13} \mathrm{~S} \mathrm{~cm}^{-1}$ and they may be considered as totally insulating materials. The sulfonation process improves significantly the ion conductivity of both polymers, especially for SPSU. In all cases, the increase of conductivity was reached after sample hydration, and systems with high proton conductivity were obtained. A clear correlation between $\sigma$ and hydration time cannot be established, but at the highest hydration time, all samples, except SPSU, present similar values of conductivity. Although, SPSU shows the best behaviour, fissures and even little holes were detected in this sample after measuring.

This fact reveals the difficulty of selecting, in this kind of systems, the most appropriate for each application because it is possible to have materials with high proton conductivity but 
Table III. Values of conductivity obtained through complex impedance spectroscopy, at different hydration times

\begin{tabular}{ccccccc}
\hline \multirow{2}{*}{$\begin{array}{c}\text { Hydration time } \\
(\mathrm{h})\end{array}$} & SPSU & SPES & SPSUSPES & SPSUPI & SPESPI & SPSUSPESPI \\
\cline { 2 - 7 } & $9.5110^{-6}$ & $2.1010^{-9}$ & $6.7010^{-7}$ & $2.5410^{-10}$ & $3.4010^{-10}$ & $5.0110^{-10}$ \\
\hline 0 & $1.6710^{-2}$ & $1.4110^{-4}$ & $1.9010^{-2}$ & $2.8810^{-6}$ & $1.7010^{-5}$ & $8.4710^{-4}$ \\
1 & $4.7110^{-2}$ & $2.1410^{-4}$ & $1.4110^{-2}$ & $2.8110^{-5}$ & $1.8010^{-5}$ & $5.2610^{-3}$ \\
2 & $2.6010^{-2}$ & $2.9710^{-4}$ & $6.3210^{-3}$ & $2.8410^{-4}$ & $4.2810^{-6}$ & $1.3210^{-3}$ \\
3 & $1.2510^{-2}$ & $3.1810^{-4}$ & $1.8410^{-3}$ & $6.5910^{-5}$ & $3.3010^{-6}$ & $4.6010^{-4}$ \\
5 & $1.3510^{-2}$ & $2.0610^{-4}$ & $1.9210^{-4}$ & $8.7810^{-5}$ & $2.0210^{-5}$ & $2.0210^{-4}$ \\
\hline
\end{tabular}
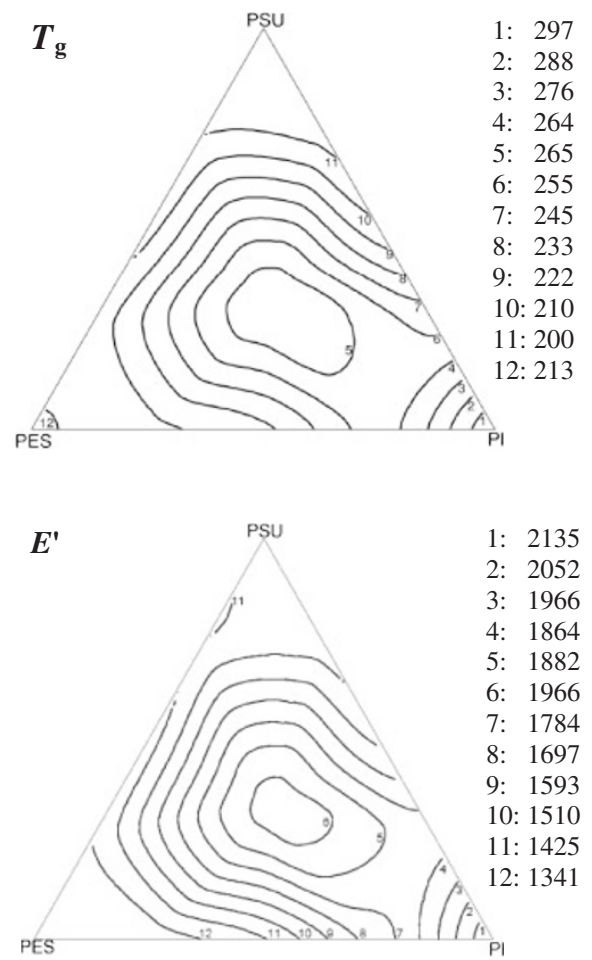
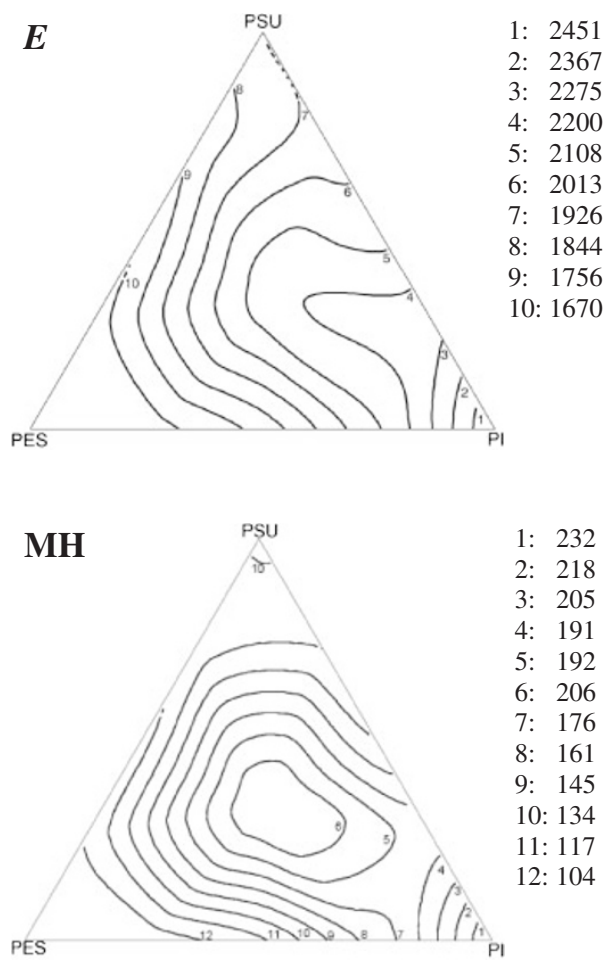

Figure 8. Response-surface contours for non-sulfonated systems.

not good mechanical properties and vice versa. Hence, it would be very useful to have a tool that allows tailoring-materials to be designed.

\section{Statistical Design}

As it has been mentioned in the experimental part of this work, in order to apply the model proposed by Scheffé, blends with the suitable compositions were prepared, and using the NEMROD 3.1 software, the following equations were obtained:

\section{Non-sulfonated Blends}

$T_{\mathrm{g}}=189 \mathrm{X}_{1}+223 \mathrm{X}_{2}+309 \mathrm{X}_{3}-4 \mathrm{X}_{1} \mathrm{X}_{2}-144 \mathrm{X}_{1} \mathrm{X}_{3}-$ $148 \mathrm{X}_{2} \mathrm{X}_{3}+1726 \mathrm{X}_{1} \mathrm{X}_{2} \mathrm{X}_{3}$

$E=1940 \mathrm{X}_{1}+1590 \mathrm{X}_{2}+2551 \mathrm{X}_{3}-320 \mathrm{X}_{1} \mathrm{X}_{2}-$

$662 \mathrm{X}_{1} \mathrm{X}_{3}-1082 \mathrm{X}_{2} \mathrm{X}_{3}+9513 \mathrm{X}_{1} \mathrm{X}_{2} \mathrm{X}_{3}$

$E^{\prime}=1480 \mathrm{X}_{1}+1310 \mathrm{X}_{2}+2290 \mathrm{X}_{3}-20 \mathrm{X}_{1} \mathrm{X}_{2}-$

$1060 \mathrm{X}_{1} \mathrm{X}_{3}-1360 \mathrm{X}_{2} \mathrm{X}_{3}+15870 \mathrm{X}_{1} \mathrm{X}_{2} \mathrm{X}_{3}$

$\mathrm{MH}=136 \mathrm{X}_{1}+101 \mathrm{X}_{2}+249 \mathrm{X}_{3}-26 \mathrm{X}_{1} \mathrm{X}_{2}-178 \mathrm{X}_{1} \mathrm{X}_{3}-$ $236 \mathrm{X}_{2} \mathrm{X}_{3}+2788 \mathrm{X}_{1} \mathrm{X}_{2} \mathrm{X}_{3}$

\section{Sulfonated Blends}

$T_{\mathrm{g}}=157 \mathrm{X}_{1}+231 \mathrm{X}_{2}+309 \mathrm{X}_{3}+40 \mathrm{X}_{1} \mathrm{X}_{2}-88 \mathrm{X}_{1} \mathrm{X}_{3}-$ $220 \mathrm{X}_{2} \mathrm{X}_{3}+849 \mathrm{X}_{1} \mathrm{X}_{2} \mathrm{X}_{3}$

$\mathrm{MH}=99 \mathrm{X}_{1}+218 \mathrm{X}_{2}+249 \mathrm{X}_{3}-22 \mathrm{X}_{1} \mathrm{X}_{2}-60 \mathrm{X}_{1} \mathrm{X}_{3}-$ $154 \mathrm{X}_{2} \mathrm{X}_{3}+1203 \mathrm{X}_{1} \mathrm{X}_{2} \mathrm{X}_{3}$

$\log \sigma=-1.87 \mathrm{X}_{1}-3.60 \mathrm{X}_{2}-14.00 \mathrm{X}_{3}-3.76 \mathrm{X}_{1} \mathrm{X}_{2}+$ $15.50 \mathrm{X}_{1} \mathrm{X}_{3}+16.58 \mathrm{X}_{2} \mathrm{X}_{3}-8.82 \mathrm{X}_{1} \mathrm{X}_{2} \mathrm{X}_{3}$

Once the equation is known, it is possible to calculate the value of the property for each composition without experimental determination. Plotting the equations, the corresponding response-surface contours are obtained, as it is shown in Figure 8 and Figure 9 for non-sulfonated and sulfonated systems, respectively. In order to prove the suitability of the proposed design, the glass transition temperature was determined, from DSC measurements, for two further blends: PSUPES $(75 / 25)$ and SPSUSPES $(75 / 25)$. The results were $198^{\circ} \mathrm{C}$ and $187^{\circ} \mathrm{C}$, respectively. The corresponding values calculated by applying the equations obtained with the model were 197 and $183^{\circ} \mathrm{C}$, respectively. Hence, the model proposed by Scheffé has proved to be suitable and reliable to examine 

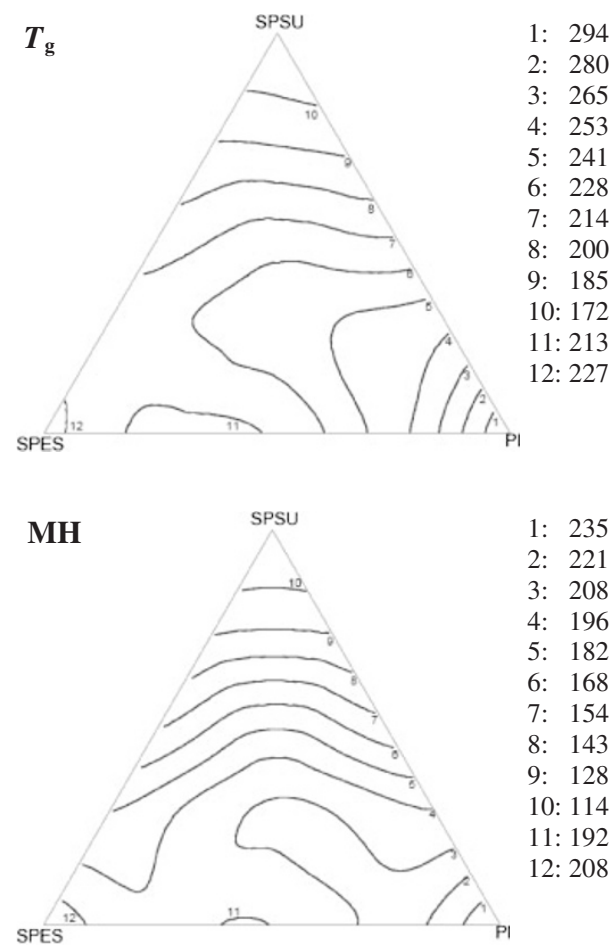

1: 235

2: 221

3: 208

4: 196

5: 182

6: 168

7: 154

8: 143

9: 128

10: 114

11: 192

12: 208

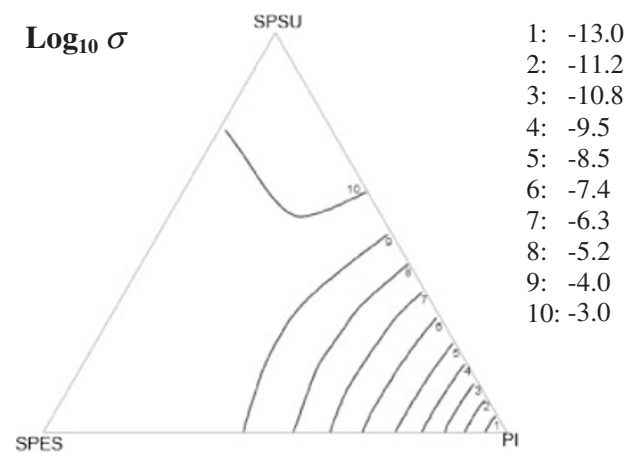

Figure 9. Response-surface contours for sulfonated systems.

these systems, as it is capable of reproducing their behaviour quite satisfactorily.

Analyzing the non-sulfonated systems, it is possible to point out the following points:

- for binary blends, the properties vary with composition, presenting values between the corresponding to both components.

- for ternary blends, the analyzed properties increase inversely proportional to PSU or PES fraction, up to a certain percentage, where the value of the property practically does not vary. Then, it begins to decrease.

- for ternary blends, every property diminishes proportionally to PI increase, but this variation is slight in the central zone.

- $T_{\mathrm{g}}, E, E^{\prime}$ and $\mathrm{MH}$ behave in the same way. The difference is the percentage at which the changes take place.

Regarding to the sulfonated systems, we can infer:

- $T_{\mathrm{g}}$ varies as a function of the blend composition and the values are comprised between the corresponding to the unblended polymers. However, in the case of SPSUSPES and SPESPI, when SPES content is higher than $50 \%$, it hardly varies. With respect to ternary blends, at low SPES content, $T_{\mathrm{g}}$ increases with PI and diminishes with SPSU. For intermediate SPES content, the glass transition temperature increases inversely proportional to SPSU, up to central levels, from which varies slightly or diminishes. At higher SPES concentration, there is a wide zone where $T_{\mathrm{g}}$ remains constant.

- $\mathrm{MH}$ behaves practically equal to $T_{\mathrm{g}}$ but in this case only SPESPI binary blend shows a very wide region where $\mathrm{MH}$ does not vary with composition.

- Conductivity varies proportionately to composition for blends with a PI percentage higher than $50 \%$, and, as it can be observed, there is a very wide region where the conductivity is almost constant no matter the composition of the blends.

\section{CONCLUSIONS}

A reaction of sulfonation, with chlorosulfonic acid, has been accomplished in polysulfone and polyethersulfone, and the sulfonation process has been assessed through infrared spectroscopy. Alternatively, blends with different compositions have been prepared and characterised by studying their thermal, mechanical, and electrical properties. All samples, sulfonated and non-sulfonated, show a single glass transition temperature varying as a function of composition. This fact suggests that these materials behave as miscible systems. A quite good relationship has been found between $\mathrm{MH}$ and $T_{\mathrm{g}}$ and between MH and Young's modulus (given by either DMTA or tensile tests) in the case of non-sulfonated systems. Taking into account these results, we propose that also a direct relationship can be established between microhardness and elastic modulus for sulfonated systems.

The design of experiences used in this work has proved to be suitable and reliable to study these systems, and lets us define the region of compositions where the properties are more favourable. In the case of ternary blends, for both nonsulfonated and sulfonated systems, the most remarkable fact is that there is a wide zone where the properties hardly vary with the composition. This result is important because allow us to prepare blends with similar properties and different composition, depending on the target to reach. For example, in the case of sulfonated blends, a composition with good properties, from an electrical and mechanical point of view, would be around $30 \%$ SPES, $25 \%$ PI and $45 \%$ SPSU.

Acknowledgment. The authors are grateful for the financial support of Ministerio de Educación y Ciencia (projects $\mathrm{n}^{\circ}$ MAT2005-00228 and ENE2004-00081/ALT).

Received: October 14, 2008 Accepted: January 29, 2009 Published: March 25, 2009 


\section{REFERENCES}

1. K. B. Prater, J. Power Sources, 51, 129 (1994).

2. T. Klaiber, J. Power Sources, 61, 61 (1996).

3. "Solid State Ionic V," G.-A. Nazri, C. Julien, and A. Rougier, Ed., Materials Research Society, Warrendale, Pennsylvania, 1999.

4. "Ionomers: Synthesis, structure, properties and applications," M. R. Tasnt, K. A. Mauritz, and G. L. Wilkes, Ed., Springer, London, 1997.

5. M. L. Di Vona, D. Marani, A. D’Epifanio, S. Licoccia, I. Beurroies, R. Denoyel, and P. Knauth, J. Membr. Sci., 304, 76 (2007).

6. L. M. Robeson, A. G. Farnham, and J. E. McGrath, "Dynamic Mechanical Characteristics of Polysulfone and Other Polyarylethers," in "Molecular Basis for Transitions and Relaxations," D. J. Meier, Ed., Midland Macromolecular Institute Monographs, 1978, Vol. 4, p 405.

7. L. M. Robeson and S. T. Crisafulli, J. Appl. Polym. Sci., 28, 2925 (1983).

8. J. F. Blanco, Q. T. Nguyen, and P. Schaetzel, J. Membr. Sci., 186, 267 (2001).

9. R. L. Oréfice and A. Brennan, Mater. Res., 1, 19 (1998).

10. R. Nolte, K. Ledjeff, M. Bauer, and R. Mülhaupt, J. Membr. Sci., 83, 211 (1993).

11. F. Wang, M. Hickner, Q. Ji, W. Harrison, J. Mecham, T. A. Zawodzinski, and J. E. McGrath, Macromol. Symp., 175, 387 (2001).

12. A. Noshay and L. M. Robeson, J. Appl. Polym. Sci., 20, 1885 (1976).

13. B. Smitha, S. Sridhar, and A. A. Khan, J. Membr. Sci., 225, 63
(2003).

14. H. Scheffé, J. Roy Statist. Soc., B25, 235 (1963).

15. B. Boitevin, G. Rigal, A. Rosseau, P. Schaeffner, D. Mathieu, and R. Phan Tan Luu, Double Liason-Chimie des Peintures, 59, 306 (1981).

16. H. Scheffé, J. Roy Statist. Soc., B20, 344 (1958).

17. M. Marcos, E. Meléndez, J. K. Serrano, D. Mathieu, R. Phan Tan Luu, and J. Elguero, Bull. Soc. Chim. Belg., 92, 429 (1983).

18. NEMROD 3.1 (1995), L.P.R.A.I., Av. Gaston Berger, F-13625 Aix-en-Provence (France).

19. M. I. Felisberti, L. L. Freitas, and R. Stadler, Polymer, 31, 1441 (1990).

20. L. A. Wood, J. Polym. Sci., 28, 319 (1958).

21. T. G. Fox, Bull. Am. Phys. Soc., 1, 123 (1956).

22. J. M. Pochan, C. L. Beatty, and D. F. Pochan, Polymer, 20, 879 (1979).

23. H. A. Schneider, Polymer, 30, 771 (1989).

24. H. A. Schneider and E. A. Di Marzio, Polymer, 33, 3453 (1992).

25. G. Zamfirova, M. Misheva, M. Kresteva, E. Pérez, J. M. Pereña M. L. Cerrada, and N. Djourelov, Polym. J., 34, 779 (2002).

26. T. Scrivani, R. Benavente, E. Pérez, and J. M. Pereña, Macromol. Chem. Phys., 202, 2547 (2001).

27. F. J. Baltá Calleja, Adv. Polym. Sci., 66, 117 (1985).

28. A. Eisenberg, B. Hird, and R. B. Moore, Macromolecules, 23, 4098 (1990).

29. B. Hird and A. Eisenberg, Macromolecules, 25, 6466 (1992). 